\title{
Strategies to effectively control Aggression: A case study
}

\author{
Kartiki Porwal ${ }^{1}$, Dr Pubalin Das ${ }^{2}$
}

\section{ABSTRACT:}

Individuals who are socially connected are happier and healthier than their more isolated counterparts. Over the past few decades, researchers have established that both the quantity and quality of our social relationships are unequivocally important when it comes to our physical and mental health, and our risk of mortality. Although the link between social relationships and mental health is well established in a couple, we have only just begun to identify explanations for this link. Recently, social scientists have discovered that the link between social relationships and health is explained by our behaviours (e.g., smoking, exercise, diet), various psychosocial factors (e.g., social support, mental health, cultural norms), and physiological processes. Aggression in marital relationship is defined as a manipulative, physical or non-physical form of aggression meant to negatively impact the development of relationship by social exclusion or harming the social status of a victim by spreading or behaving negatively. Research findings suggest that even infrequent experiences with relational aggression victimization are associated with lower subjective well-being such as depression, loneliness, and positive affect. This case study investigates the existence of relational aggression in a couple and the relationship between relational aggression and own subjective well-being. The participant in the study is married and from nuclear family. The study tries to investigate aggression level through the case study method and relaxation, yoga, meditation techniques used which was used to resolve the aggression and helps to achieve well being.

Keywords: Aggression, Relaxation, yoga, meditation.

Aggression is a kind of harmful social interaction with the intension of inflicting damage or destruction upon another individual. It may occur without provocation or may be frustration due to blocked goals can cause aggression. Being aggressive is not at all good as it takes away the communication between our minds our body. Aggression is that feeling of mind in which we get tensed and angry over wanted or unwanted reasons. Any person who gets angry over silly reasons is considered to be a troublemaker even though he may actually be a good person. Aggression simply gives a sudden satisfaction of mind while we are in a raised situation but the after effects which it brings to us are not easy to be handled.

\footnotetext{
${ }^{1}$ Indian Institute of Psychology

${ }^{2}$ Indian Institute of Psychology
} 
You might get aggressive for a reason which we think is right, but for the other person or group of people who listens to you might not feel great about it. Being aggressive can usually destroy the depth of relation between two people, even without the knowledge of the one who is being aggressive. Aggression as a behavioural phenomenon indicates that Aggression Behaviour may stem from learned habits of responding as well as from excessive (Bandura 1965). It may be expressed in terms of irritation; quarrelling and fighting disrespect to elder's negative reaction to traditional and believes etc. Mc Clelland and Apicella (1945) have also done significant works, in the context of Frustration-aggression hypothesis, by creating frustration in the laboratory. Aggression at work is usually defined as any form of aggressive behaviour with the intention to harm the victim and the behaviour used may be both physical and psychological in nature (Baron \& Neuman, 1998; Baron \& Richardson, 1994; Geen, 1990). The society simply puts aside those people who gets angry over small reasons, and never cares about what that person says even in a complicated problem over which he might have a large number of ideas or suggestion. Being aggressive also puts us into a tedious approach to the on goings after the angry situation as we keep on thinking about the problem again and again. Too much of unwanted thoughts also have bad effects on our mental stability and physical capabilities. Verbal and psychological aggression seems to be more prevalent than physical aggression and violence (Baron \& Neuman,1996; Bulatao \& VandenBos, 1998; Di Martino, Hoel, \& Cooper, 2003). Physical-verbal aggression is defined according to whether the aggression is expressed through physical acts like hitting or verbal acts such as threats. Once we are angry, we cannot focus on what is happening around us but just on how we can make the other fellow understand what our mindset is or what kind of a suggestion we would like to present. The feeling which usually gets people to be aggressive is that when they think of themselves as they cannot handle the situations in their life. But once a person gains confidence over his own abilities, any consequences in life can be handled within no sweat. And also, the people who cares for the happiness of other people rather than their own, usually has a clear perspective of what to do and does not indulge in unwanted problems.We might be thinking to limit ourselves, but our body simply works on its own. The situation will be turn into mess.

\section{AGGRESSION AND RELATIONSHIP}

Aggressiveness is a mode of communication and behaviour where one partner expresses their feelings, needs and rights without regard or respect for the needs, rights and feeling of others. However, considering both partners' aggression allows for a more complete understanding of dysfunction in the relationship system, especially because aggression may be an interactive and synergistic phenomenon for some couples (Vivian \& Langhinrichsen-Rohling, 1994). Emotion or physical forces are often used and person feel victimised and their relationships suffer. .Furthermore, similar to physical aggression, emotional aggression is often bidirectional (Hines \& Saudino, 2003; Swan \& Snow, 2002). Although the perpetration of emotional and physical aggression is highly correlated (Hamby \& Sugarman, 1999; Hines \& Saudino, 2003; Murphy \& O'Leary, 1989), little is known about the trajectory of emotional aggression over time, and whether it follows a similar pattern as physical aggression In relationship aggression is not good 
for the aggressor and as well as the partner facing aggression. The relationship conflict leads to stress and it affects both the partner in many ways. It can impact on their relationship and stress level and it can also affect on their health and happiness. Now a day's different strategies were used to control aggression like yoga, meditation, relaxation etc are being introduced to minimise the stress level and aggression among the individual .The yoga plays an important role in keeping the stress level and aggression down and also helps to improve the concentration power and to keep them calm and relax and more focused towards their goals. Moreover, importance should be given to the above mentioned strategies more and more over stress level and aggression will automatically become low when individual are healthy. So, such steps should be taken by every individual to improve themselves and to live a happy and peaceful life and help us to reach their desired goals. Temple, Weston, \& Marshall (2005), for found that aggression is more severe and frequent in relationships where both partners are aggressive.

\section{OBJECTIVE OF THE STUDY}

The main objective of the study is to see the impact of relaxation, yoga and meditation to control aggression which leads to a happy and healthy life.

\section{CASE STUDY}

In the present research case study method is used. In the present case study, a couple who were happily living but after many years spending together but now they are facing aggression and disturbed family environment. Interview was done to select the participant. The Participant of the present study Raghav Arora (name changed) aged 25, who was married from last 2years and according to him he was very happily living with his partner but in the past due to blocking of goals and facing lot of failures leads to anger, hatred, de-motivation and aggression. It was also put impact on his married life, regular fight were common in their life, love decreases and fights increases.

After the interview with the participant, his wife and other family members it was concluded that due to his aggression the whole family is being victim of it and all are suffering for the same. It was a deep study to understand how aggression is affecting his life. In the present study confidentially was maintained so he could open up without any hesitation.

Earlier he was working in Private sector but now he is not working. He is preparing himself for government job. He is eldest in his family, he has younger sister. He had lost his father when he was in 10th standard and his mother is house wife. He is very close to his mother and very friendly in nature. He feels comfortable and happy with those whom he is close too. He was in relationship from last 5 years and now he got married. Raghav is close to two of his childhood friends and his wife who was earlier his girl friend. He has done engineering and 2 years he 


\section{Strategies to effectively control Aggression: A case study}

worked in private sector and according to him in private sector he has to give lot of input but output is low being eldest in the family he has responsibility of everyone in his family like mother, sister, wife. He decided to give up private job and start preparing for government job exams. This was very big decision for him and for his family as there was no one earning in the family. When he was in 10th class his father passed away, at that time he has faced mental pressure to stand himself and to support his family to secure their future and to fulfil their basic necessity. From class 10th till engineering he was under pressure and he got continuous support from his other family members and motivated him to study. After the completion that he got job and got engaged with his girl friend, both the families were very happy. In his job his income was nominal and he was facing difficulty to fulfil the demands of everyone. From that time he had started facing a lot of mood swings, stress and anger because of lot of work pressure and family pressure. There was continuous support from his Fiancé they both partner had a very good understanding level and very high compatibility. She understands him at every point and motivated him to work. She was the one who helps him to balance his emotions, feelings etc. When Raghav sees a competition level is too high and his friends were earning was much better than him makes him more anxious and worried because he has lot of responsibility and then he decided to give up private job and to prepare for government job exams. During this time his stress and aggression level increased a lot he started showing mood swings, irritation, frustration, he wants to live alone all the time. Negative thoughts were increased and feels highly demotivate. He doesn't want to spend time with his childhood friends and his Fiancé with whom he feels more relaxed and comfortable. He started ignoring them. He was socially isolated. There was lot of disturbance in sleeping patterns. He feels lethargic. He feels anxious and not able to concentrate on his studies. There were lots of thoughts popping in his mind related to his future which was making him more and more anxious. His relationship started destroying with his mother, sister and Fiancé. His fights increased with them. They give him some suggestion but he takes everything negatively. He become short tempered and shouts on everyone. He tries to be commanding and dominating .he started avoiding his Fiancé, he doesn't want to spend time with her. Their relationship started ruining .Both the partner faced lot of difficulty to understand each other in that difficult situation but Raghav attitude was very negative and aggressive which is very problematic for both of them. There were many times in his life he was considered too aggressive to be talked with. His family member stopped commanding him as they felt that it would not give them positive reply and instead just tear through them. When people accuse him of mistake which he did not commit, he used to get as angry over the matter as the only thing he feel like is to prove his innocence, But unknowingly, by being aggressive, he was a stubborn and spoilt person .His aggressiveness has affected his life in a relatively bad manner. He literally went away from his house, shouted at his family member and fiancé, insulted anyone who confronted him with advice and threw away those sympathetic people who regretted for his situation .His fiancé whom he used to be very close with, started telling him that she is worried about his sudden reactions and bad approach to several problems in his life. Showing sympathy was something she always did. Hence he threw her out of his life and wants to be separate from her and feels that she is not close to him anymore. 


\section{Strategies to effectively control Aggression: A case study}

After taking the interview from his family and Fiancé and regular interaction with Raghav found lot of issue in his behaviour. To keep his mind and body calm and balanced form we have done 12-15 sessions, one hour each with him. The main intension of this intervention was to focus on his positive behaviour, work on his hobbies and interest. Relaxation techniques was used to control his aggression to keep his mind and body calm, avoid negative thoughts .with relaxation techniques we have also asked him to add other effective strategies like yoga, meditation in his daily routine which will help him to control aggression. In the starting he doesn't pay attention but gradually he started showing interest and started cooperating with us .After the intervention there was changes in his behaviour he was quite calm and relax he started understanding the things in a right way. less anxious and worried. Reduce in mood swings. He feels positive and energetic to do his work .motivational level increased. Don't shout and fight with his family member and fiancé. He started realising fiancée importance in his life. He wants her back in his life. He feels incomplete without her. He started balancing his emotions feelings etc feels sorry for his behaviour, and got married.

\section{DISCUSSION AND CONCLUSION}

It is generally found that aggression and stress level have been found more in boys than girl as shown in the study. Boy have more aggression due to the fact that parents have a feeling that boys are more capable of handling their property and business including other household and social responsibility, family has higher expectation from the males to excel in life. Due to this fact parents expect more from boys. This is a major cause of increasing aggression level in the participant. Some individual are not capable of handling so much aggression and stress and they find it easier to escape from the situation rather than living a life full of aggression and stress. As a result divorced rate or separation among couples is increasing at a fast rate. Moreover Family and wife expectation on their husband or son is increasing day by day which is another cause of increasing aggression level among individual. In today's time High completion level and nominal income creates lot of pressure to fulfil demands and responsibility of his family. Sometime the individual are influenced by the society in which they are living and trying to fulfil their demand and responsibility and to maintain there status. All these factors affect the couple relationship their emotions, understanding and feelings. It was believed that they should understand each other and balance themselves to settle or manage their relationship and family. Keeping our mind and body calm is one of the best ways to control aggressiveness. Although female victims are often the focus of intimate violence research, the considerable rates of aggression towards men (e.g. Archer, 2000) suggest the need to evaluate both male and female aggression. Clearly women suffer more severe consequences due to partner aggression (Archer, 2000; Holtzworth-Munroe, Smutzler, \& Bates, 1997) and the context of and motivations for

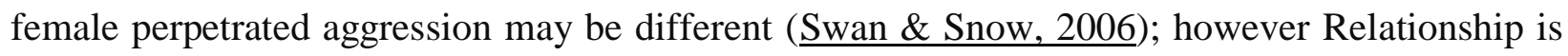
destroyed because of aggression that one of the partner is more aggressive and commanding which cause difference in their relationship.Controlling our anger is not easy but there are many ways to control it if we have the confidence. There are effective strategies which provide help to those people who cannot keep control over their state of mind in certain situations. Meditating in 


\section{Strategies to effectively control Aggression: A case study}

the morning at a calm and lonely place which keeps our mind fresh, keeping ourselves engaged in good company etc. Daily start walking and doing relaxation techniques .Start knowing your positive aspect of your life. Usually aggressiveness cannot be controlled at the moment unless we have a calm and peaceful mind or else we should be practised to keep ourselves in control. These techniques can be used with wider range to maintain wellbeing of married couples.

\section{REFERENCES}

1. Bandura, A. (1965): Vicarious processes: a case of no -trial learning. In L. Berkowitz (ed.) Advances in Experimental Psychology, New York, Academic press.

2. Baron RM, Kenny DA. (1986). the moderator-mediator variable distinction in social psychological research: Conceptual, strategic, and statistical considerations. Journal of Personality and Social Psychology; 51(6):1173-1182.

3. Clelland, D.C. \& Apicella, F.S. (1945)"A Functional Classification of Verbal reactions to experimentally included failure. Journal of Abnormal and Social psychology, 40: 376390.

4. Maier, N.R.F. (1956),"Frustration: The study of behaviour without a goal, New York, McGraw hill. 8. Mc

5. Neuman JH, Baron RA.(1997). Aggression in the workplace. In: Giacalone RA, Greenberg J, editors. Antisocial Behaviour in Organizations. London, New Delhi: Sage Publications, 37-67. 